\title{
COMENTARIOS SOBRE LA RESPONSABILIDAD SOCIAL EMPRESARIAL, EL DERECHO SOCIETARIO Y LA EMPRESA DE GRUPO*
}

\section{REMARKS ON CORPORATE SOCIAL RESPONSIBILITY, COMPANY LAW, AND GROUPS OF COMPANIES}

\author{
Fabio Andrés Bonilla-Sanabria** \\ Fecha de recepción: 28 de agosto de 2016 \\ Fecha de aceptación: 18 de noviembre de 2016 \\ Disponible en línea: 30 de mayo de 2017
}

\section{Para citar este artículo/To cite this article}

\begin{abstract}
Bonilla-Sanabria, Fabio Andrés, Comentarios sobre la responsabilidad social empresarial, el derecho societario y la empresa de grupo, 134 Vniversitas, 21-58 (2017). http://dx.doi.org/10.11144/Javeriana.vj134.crse
\end{abstract}

doi:10.11144/Javeriana.vj134.crse

* Este artículo es producto de la investigación del grupo de investigación Derecho Comercial Colombiano y Comparado, departamento de Derecho Comercial, Universidad Externado de Colombia. Un primer resultado de esta investigación fue presentado como ponencia en las Jornadas de Derecho Comercial: Sociedades y Empresa de Grupo, realizadas en la Universidad Externado de Colombia el 5 y 6 de septiembre de 2014.

** Abogado y especialista en derecho comercial, Universidad Externado de Colombia. Becario de Colfuturo y de la Universidad Externado para desarrollar el programa LLM en Derecho Internacional de los Negocios del University College of London (UCL), en donde se graduó con mérito. Docente e investigador del Departamento de Derecho Comercial, Universidad Externado. Abogado consultor en temas de derecho comercial y societario. Contacto: Fabio.bonilla@uexternado.edu.co 


\section{RESUMEN}

El artículo presenta las implicaciones de la responsabilidad social de la empresa (RSE) para el derecho societario, y su aplicación en el contexto de los grupos empresariales. En primer lugar, aborda la conceptualización y las razones del auge de la RSE en el discurso societario moderno. Posteriormente, menciona algunas dificultades de la aplicación de esta figura en los deberes de los administradores. Por último, el artículo describe la forma en que la RSE puede funcionar en la estructura grupal de la empresa y señala unos posibles efectos positivos de su aplicación en esta estructura empresarial compleja.

Palabras clave: Derecho societario; responsabilidad social empresarial; sostenibilidad; grupos empresariales 


\section{ABSTRACT}

This article discusses the implications of Corporate Social Responsibility (CSR) in Company Law, and its applicability in the context of Groups of Companies. The article initially draws on the concept of CSR and its importance in modern corporate topics. In the following section, the article covers some challenges of the applicability of the CSR doctrine vis-à-vis director duties. The article then explains the manner in which CSR functions in Groups of Companies relating some potential benefits of its application within this complex company structure.

Keywords: company law; corporate social responsibility; sustainability; groups of companies

\section{SUMARIO}

INTRODUCCIÓN.- I. LAS RAZONES DEL AUGE DEL DISCURSO DE LA RESPONSABILIDAD Social Empresarial.- $A$. Las inequidades del proceso de globalización económica.- B. La permeabilidad del discurso de los derechos humanos al derecho empresarial.- C. Las tecnologías de la información y la reputación organizacional.- II. LA CONCEPTUALIZACIÓN DE LA RESPONSABILIDAD SOCIAL EMPRESARIAL.- III. DifiCUlTADES JURÍDICAS DE LA RSE: LA PRIORIZACIÓN DE LOS GRUPOS DE INTERÉS Y SU CARÁCTER VOLUNTARIO.- IV. IMPLICACIONES PARA El DERECho Societario Del Discurso De la RSE.- $A$. El caso del Reino Unido.- B. La regulación en Colombia y su interpretación constitucional.- V. EL ROL DE LA EMPRESA DE GRUPO FRENTE A LA RESPONSABILIDAD SOCIAl EMPRESARIAL.- $A$. La RSE como parte de la unidad de propósito y dirección.- B. La RSE como un deber de los administradores de la empresa de grupo.- $C$. La homogeneización de prácticas empresariales en los grupos multinacionales y el efecto transnacional de la regulación que les es aplicable.- D. El acceso a fuentes de financiación socialmente responsables.- E. El efecto multiplicador.- Conclusiones.- Bibliografía. 


\section{INTRODUCCIÓN}

Este documento pretende presentar algunas consideraciones con relación a la responsabilidad social empresarial (en adelante, RSE) como área de estudio que afecta el derecho societario, y su posible relación con la estructura grupal de la empresa. El artículo revisará algunos temas básicos de la responsabilidad social, entendida como una tendencia a considerar el impacto de la empresa en su entorno, en las prácticas de gobierno empresarial y la forma en que esto se puede reflejar en la estructura grupal de la empresa.

El presente documento mencionará en primer lugar las razones que pueden justificar el auge actual del discurso de RSE. En segundo lugar, y con el propósito de dar un poco de claridad conceptual sobre ese tema, haré una mención al concepto de lo que se entiende o debería entenderse por esta. A continuación, se señalan algunos retos desde el punto de vista del estudio jurídico, para finalizar con algunas posibles implicaciones para el derecho societario, $\mathrm{y}$ en particular para la empresa de grupo.

\section{LAS RAZONES DEL AUGE DEL DISCURSO DE LA RESPONSABILIDAD SOCIAL EMPRESARIAL}

Sin duda, tanto en el ámbito de la administración de empresas como en el discurso jurídico, la responsabilidad social empresarial y la sostenibilidad de la empresa se han vuelto temas recurrentes ${ }^{1}$. Por supuesto, el tema del impacto de la empresa en la vida en sociedad no es un asunto novedoso y antecedentes sobre el tema existen en muchos países desde hace varios años. Sin embargo, en este documento, mi intención es presentar el tema de una forma un tanto

1 En realidad, el tema se aborda desde múltiples ángulos. La sostenibilidad de los negocios, la creación de valor compartido, la prevalencia de la visión de largo plazo, entre otros, son todas formas de ver el mismo tema: la compaginación de las prácticas comerciales y de los negocios con realidades sociales. En 2014, la revista The Economist publicó una entrevista con Barack Obama, presidente de Estados Unidos en esa época, en la que este comenta que si bien hay que reconocer una mayor preocupación de las empresas por otros stakeholders, los CEO de las empresas siguen teniendo una visión enfocada en sus accionistas. El entrevistador contraargumenta que hay una gran preocupación de los administradores de las empresas por esos grupos y que en la práctica, estos dedican gran parte de su tiempo a lidiar con asuntos relacionados con ellos. An Interview with the President. Barack Obama Talks to the Economist, The Economist, August 2, 2014. Disponible en: http://www. economist.com/blogs/democracyinamerica/2014/08/barack-obama-talks-economist 
diferente con el propósito de hacer una mención sobre las razones que han contribuido a que en la actualidad el tema no sea si las empresas tienen o no un impacto sobre las sociedades en las que funcionan, sino la forma en que se debe considerar y manejar ese impacto.

Brevemente, conforme lo sostiene Jerome J. Shestack ${ }^{2}$, en la actualidad se habla con tanta frecuencia del discurso de la RSE por tres razones: la globalización, los derechos humanos y agregaría a estas dos, las tecnologías de la información. Si bien mencionaremos la forma en que cada uno de estos elementos contribuye a este auge, su combinación es la que construyó un ambiente socioeconómico en el cual las empresas no son un actor aislado en su entorno y por el contrario cada vez más se espera de ellas un rol activo frente a grupos de interés tradicionalmente vistos como externos para la empresa.

\section{A. Las inequidades del proceso de globalización económica}

La política económica adoptada por la gran mayoría de los países del planeta ha optado por el modelo de la liberación de barreras para la realización de actividades mercantiles. Este proceso de globalización (o mundialización) económica se adoptó como la mejor forma de generar riqueza; correlativamente, se sostiene que es la forma más eficiente de disminuir la pobreza en el mundo. Ahora bien, en la medida en que la promesa de generar riqueza económica y desarrollo no se ha cumplido de forma equitativa, necesariamente surgen cuestionamientos ante las expectativas no cumplidas.

Si bien como consecuencia de la adopción de las políticas económicas de comercio global no se ha redistribuido la riqueza de forma equitativa ni con base en criterios geográficos, o sectoriales, sí hay un actor económico del comercio globalizado que ha resul-

2 Si bien el autor solo menciona los derechos humanos y la globalización como las causas del cambio de pensamiento moderno sobre la RSE, en su planteamiento es posible encontrar la tercera causa de forma indirecta. Jerome J. SHeStACK, Corporate Social Responsibility in a Changing Corporate World, en Corporate Social Responsibility: The Corporate Governance of the $21^{\text {st }}$ Century, Chapter 6, 97-109 (RAmon Mullerat, ed., Kluwer Law International \& International Bar Association, London, 2005). 
tado particularmente beneficiado con estas políticas: las empresas multinacionales.

En efecto, las empresas multinacionales (que en términos de estructura técnica societaria son por lo general una manifestación de la empresa de grupo) han logrado beneficiarse de las políticas de apertura y eliminación de las barreras al comercio internacional. En no pocos escenarios se reconocen el impacto y la capacidad de influir de algunas empresas multinacionales, sobre todo cuando entre las economías más grandes del planeta hay no solo estados, sino también este tipo de empresas ${ }^{3}$. Este contexto ha dado lugar a que en un mundo que se siente cada vez más pequeño, otros agentes del comercio internacional como los gobiernos e, incluso, la sociedad civil empiecen a exigir a las empresas un mayor papel con relación a problemas sociales.

Así, entonces, si se acepta el planteamiento de que la globalización ha sido un factor de empoderamiento de las empresas multinacionales, este aumento en su poder económico ha legitimado la exigencia de comportamientos responsables a favor de grupos de interés que resultan afectados de una u otra manera por ellas ${ }^{4}$. Esto que algunos conocen como la licencia de operación de las empresas en la sociedad ${ }^{5}$, es la aplicación del principio quid pro

3 En un comentario publicado en el año 2000, los investigadores Sarah Anderson y John Cavanagh de la ONG Corporate Watch, entidad que tiene como propósito que las empresas rindan cuentas ante el público, los autores enlistan como uno de sus hallazgos el hecho de que 51 de las 100 economías más grandes del mundo correspondían a sociedades comerciales, mientras que las 49 restantes eran Estados: Sarah Anderson \& John Cavanagh, The Top 200: The Rise of Corporate Power (Global Public Forum, 2000). Disponible en: https://www.globalpolicy.org/component/content/ article/221/47211.html

4 "In this era of globalization, multi-national corporations can be so powerful with both political and economic strength that they cannot be readily controlled by national governments, particularly governments in developing countries. That power facilitates the ability of multinational corporations to further socially responsable programs if they so choose, but also to be blamed if such programs do not emerge. In short, with power comes responsibility". Jerome J. Shestack, Corporate Social Responsibility in a Changing Corporate World, en Corporate Social Responsibility: The Corporate Governance of the 21 $1^{\text {st }}$ Century, Chapter 6, 97-109 (RamOn Mullerat, ed., Kluwer Law International \& International Bar Association, London, 2005).

5 Kathleen Wilburn \& Ralph Wilburn, Achieving Social License to Operate Using Stakeholder Theory, 4 Journal of International Business Ethics, 2, 3-16, 4 (2011). Disponible en: http://www. scholarspress.us/journals/JIBE/pdf/JIBE-2-2011/v4n211-art1.pdf. Al definir lo que se entiende por licencia social para operar, estos autores citan la siguiente definición: "The concept of a Social License to Operate is defined as: 'outside of the government or legally-granted right to operate a business. A company can only gain a Social License to Operate through the broad acceptance of its activities by society or the local community. Without this approval, a business may not be able to carry on its activities without incurring serious delays and costs (The Ethical Funds Company, 2009)",, 4. 
quo - ante un mayor poder, una mayor responsabilidad de los agentes empresariales-.

\section{B. La permeabilidad del discurso de los derechos humanos al derecho empresarial}

Se dice que en los años 60 el poeta y escritor estadounidense Archibald MacLeish hizo una ahora famosa profecía consistente en decir que los derechos humanos (y no el comunismo) serían la verdadera revolución del siglo $\mathrm{XX}^{6}$. Por supuesto, en retrospectiva, esta afirmación no carece de verdad. Con posterioridad a la Segunda Guerra Mundial, en gran medida, la comunidad internacional ha dedicado sus esfuerzos a establecer y promover valores mínimos comunes que deben ser respetados en el mundo entero sin importar las tendencias económicas, políticas o religiosas que todavía existen en el planeta.

La proliferación del discurso de los derechos humanos, que en la actualidad abarca asuntos tan variados como los derechos de los trabajadores, de la mujer, de los niños, los derechos culturales, el derecho a la salud y a la seguridad social, para solo mencionar algunos de los temas a que se refieren los instrumentos internacionales en materia de derechos humanos, ha logrado que estos hayan dejado de ser ajenos al mundo comercial y de los negocios, de modo que ahora hay un área en la que confluyen el derecho empresarial y los derechos humanos?

Por supuesto, durante mucho tiempo prevaleció la idea de que el tema de los Derechos Humanos era un asunto de políticas públicas que, por lo tanto, era del resorte exclusivo de gobiernos y organizaciones internacionales, y de que el papel de las empresas era tan solo el de asumir un deber general de cumplimiento de tales derechos, sin que se esperara de ellas un rol activo en su promoción o defensa.

6 Jerome J. SHeStack, Glasnost and Human Rights (Annual Lecture, Rothschild Foster Human Rights Trust, 1989). Disponible en: http://www.rothschildfostertrust.com/materials/lecture shestack.pdf

7 Peter Muchlinski, Human Rights and Multinationals: Is there a Problem?, 77 International Affairs, 1, 31-48 (2001). Adicionalmente, resulta indicativo mencionar que los dos primeros principios contenidos en el Pacto Mundial de las Naciones Unidas (UN Global Compact) se refieren de forma expresa al rol (voluntario, eso sí) que deben asumir las empresas frente a temas de derechos humanos. Organización de Naciones Unidas, ONU, Los 10 Principios del Pacto Mundial. Disponible en: http://www.pactoglobal-colombia.org/index.php/sobre-pacto-global/los-diez-principios 
No obstante, bien sea que se trate de asuntos que afectan las relaciones internas de la empresa y los derechos de sus trabajadores, o que se trate de asuntos que afectan de forma indirecta su funcionamiento, como la corrupción o las violaciones de derechos humanos en un país en el que opera, entendidos en sentido lato, los Derechos Humanos han dejado de ser un asunto que sea completamente ajeno al funcionamiento de las empresas.

En ese sentido, y en especial considerando el primer punto del auge del discurso de la responsabilidad social de la empresa, cuando este se relaciona con las ventajas económicas que han adquirido las empresas como agentes económicos en el actual sistema de mercado mundial, resulta por lo menos entendible que las dificultades o los asuntos en materia de derechos humanos hagan surgir inquietudes acerca del rol que pueden o deben cumplir las empresas con relación a esta temática. De forma más general, se afirma que la RSE se ha vuelto entonces el medio por el cual se vincula a la empresa con asuntos que mirados de forma aislada corresponden tradicionalmente a la óptica de los derechos humanos y que por lo tanto solían serle completamente ajenos.

\section{Las tecnologías de la información y la reputación organizacional}

En tercer lugar, otro factor del auge de la RSE son las tecnologías de la información (TIC). En la actualidad, vivimos en una era tecnológica que tiene efectos sobre todas las áreas de la actividad humana, incluyendo por supuesto las empresariales. Así, las empresas utilizan las tecnologías de la información para mejorar sus procesos productivos o de administración, pero también para establecer relaciones con sus clientes o consumidores. Correlativamente, los consumidores encuentran en estas tecnologías herramientas indispensables que sirven de guía al acudir al mercado para satisfacer sus necesidades de consumo.

Esta función de las TIC en la relación entre consumidores y empresas, a la vez de servir a los consumidores para elegir y a las empresas para darse a conocer y mantener contacto con sus clientes, igualmente ha hecho que los eventos de riesgo reputacional que afectan a las empresas puedan tener un mayor impacto. De 
esta forma, asuntos que antes podrían no ser relevantes para una empresa, como los bajos estándares laborales existentes en la sede de producción de un proveedor de insumos ubicado en otro continente, se convierten en relevantes, debido a que las tecnologías de la información permiten a los consumidores y en general al mercado tener acceso a esa información que podría de alguna forma afectar su desempeño en los mercados públicos, si cotizan sus acciones allí, o en todo caso frente a los consumidores que con base en esta pueden cambiar sus preferencias al tomar una decisión de compra.

\title{
II. LA CONCEPTUALIZACIÓN DE LA RESPONSABILIDAD SOCIAL EMPRESARIAL
}

\author{
Por estas razones se ha dado un auge en el discurso de la RSE. No \\ obstante, considero apropiado clarificar brevemente a qué se hace \\ mención cuando se utiliza este concepto.
}

En realidad, el entendimiento de lo que abarca la RSE no ha sido unívoco y, por el contrario, son muchas las definiciones adoptadas bien por entidades gubernamentales ${ }^{8}{ }^{9}$, las instituciones académi-

8 En el Reino Unido, que en algún momento creó un ministerio para la responsabilidad social empresarial, el gobierno definió el concepto de RSE de la siguiente manera: "The Government sees [CSR] as the business contribution to our sustainable development goals. Essentially it is about how business takes account of its economic, social and environmental impacts in the way it operates - maximising the benefits and minimising the downsides-. Specifically, we see [CSR] as the voluntary actions that business can take, over and above compliance with minimum legal requirements, to address both its own competitive interests and the interests of wider society". Corporate Social Responsibility, http://www.csr.gov.uk. Esta definición resalta la posibilidad de que el funcionamiento de una empresa tenga un impacto positivo en el desarrollo sostenible de su entorno, lo cual se refleja en el conjunto de acciones voluntarias que toma una empresa y que implica comportamientos que van más allá de las exigencias legales, desarrollados con el propósito de cumplir objetivos competitivos $\mathrm{y}$ de la sociedad en general.

9 En el contexto nacional, la Superintendencia de Sociedades, en respuesta a una consulta hecha por un ciudadano, conceptuó que si bien en Colombia no existen disposiciones normativas que regulen expresamente la RSE, con fundamento en definiciones doctrinales esta se debe entender: "como una herramienta importante para garantizar el éxito y la sostenibilidad de cualquier modelo de negocio. Al incluir una vertiente de comercio justo en el plan de RSE la empresa facilita la cohesión de los grupos de interés, mejora la comunicación con empleados y clientes y demuestra en forma objetiva y creíble el alto grado de responsabilidad de su actividad empresarial”. Adicionalmente, el concepto identifica los potenciales beneficios que adoptar prácticas de RSE tiene para los diferentes grupos de interés involucrados en una sociedad comercial y para ella en sí misma. En este último evento, el concepto resalta los beneficios que por concepto de donaciones hechas a fundaciones y corporaciones o a obras de beneficencia pueda hacer una sociedad. Al respecto, Superintendencia de Sociedades, Oficio 220-014835, 8 de febrero de 2013. Disponible en: http://www.supersociedades. gov.co/superintendencia/normatividad/conceptos/conceptos-juridicos/Normatividad\%20Conceptos \%20Juridicos/32966.pdf 
cas $^{10}$, privadas $^{11}$ e instrumentos internacionales ${ }^{12}$, que a pesar de ello permiten identificar algunas características principales de lo que hace referencia a ella.

En un ejercicio de abstracción frente a las diversas definiciones que resaltan diferentes aspectos de la RSE, en este documento es posible decir simplemente que la RSE es la relación que existe entre la empresa y la sociedad. No obstante, justamente con el propósito de dar un poco más de sustancia a este concepto, sostengo la posición de que la responsabilidad social empresarial consiste en la aceptación de la realidad de que el funcionamiento de una empresa es un asunto que afecta los intereses no solo de los aportantes de capital o de los administradores de una sociedad comercial, sino que también involucra a otros grupos como los trabajadores, los clientes o consumidores de los productos y servicios ofrecidos por la empresa, y la localidad en la que está ubicada geográficamente, el Estado, el medio ambiente, etc.

Ahora bien, más allá del reconocimiento de esta realidad práctica, la RSE significa en últimas la implementación de comportamien-

10 La escuela de Administración Pública de la Universidad de Harvard, Kennedy School of Government, en particular el programa The CSR Initiative, propuso la siguiente definición en una de sus publicaciones: "The term [CSR] is often used interchangeably with corporate responsibility, corporate citizenship, social enterprise, sustainability, sustainable development, triple bottom line, corporate ethics, and in some cases corporate governance. Though these terms are different, they all point in the same direction: throughout the industrialized world and in many developing countries there has been a sharp escalation in the social roles corporations are expected to play. Companies are facing new demands to engage in public-private partnerships and are under growing pressure to be accountable not only to shareholders, but also to stakeholders such as employees, consumers, suppliers, local communities, policymakers and society-at-large". La anterior definición resulta de particular interés en la medida en que reconoce la existencia de múltiples conceptos que tienen un elemento común y reflejan un cambio en la concepción del papel social que se espera de las sociedades comerciales tanto en países desarrollados como en vía de desarrollo, deja de lado la idea de que solo son responsables o deben "rendir cuentas" frente a sus socios.

11 Un tercer concepto de lo que se entiende por RSE corresponde al utilizado por el Banco Interamericano de Desarrollo, que lo define en los siguientes términos: "We define corporate social responsibility as a business strategy that seeks to avoid causing damage to stakeholders through its activities, and wherever possible to bring them benefits, irrespective of whether the damage or benefits are subjects [sic] to legislation or regulation". En esta definición, el énfasis es determinar que se trata de una estrategia de negocios destinada a evitar que el desarrollo del objeto social cause un daño a los grupos de interés que están relacionados con la empresa y siempre que ello sea posible debe por el contrario beneficiarlos. Se trata entonces de una conducta en principio preventiva frente a terceros, pero adicionalmente, y aquí yace la novedad de la definición, admite que no necesariamente se debe tratar de conductas voluntarias, que se pueden reflejar en normas legales vinculantes.

12 Si bien el Pacto Mundial de las Naciones Unidas (UN Global Compact), en el conjunto de sus principios no define lo que debe entenderse por RSE, el desarrollo de sus principios sí es una referencia útil sobre el alcance de la misma. Adicionalmente, los tratados de libre comercio con algunos países, por ejemplo Canadá, suelen incluir cláusulas sobre RSE. 
tos empresariales que en el desarrollo de la actividad de la empresa benefician o articulan productivamente esos intereses. El carácter voluntario o vinculante de este tipo de prácticas debe ser analizado en cada caso concreto; sin embargo, la tendencia principal es la de entender que es un tema eminentemente voluntario. Entendido de esa forma, hay una clara coherencia entre la aspiración de prácticas comerciales sostenibles, las cuales usualmente se entienden como aquellas que permiten satisfacer las necesidades del presente sin sacrificar las posibilidades futuras, y la RSE como un mecanismo o instrumento útil para lograrlas.

El concepto así delineado permite hacer la diferenciación entre la RSE y otros conceptos similares, en particular el de filantropía empresarial. En efecto, si entendemos la RSE como una adaptación de la actividad u objeto de la empresa a sus grupos de interés, no sería acertado considerar que los comportamientos filantrópicos necesariamente corresponden a una expresión de aquella ${ }^{13}$. El punto entonces no es el de la deseabilidad moral de las conductas empresariales ${ }^{14}$. La idea de que las empresas deben aplicar un comportamiento socialmente responsable busca la transformación de los procesos productivos de modo que pueda lograrse la coexistencia entre la actividad productiva y el desarrollo económico sostenible.

En la práctica, es evidente la tendencia a considerar que la empresa tiene un comportamiento socialmente responsable, si tiene un programa de donaciones, siembra árboles o en la época navideña

13 En la ponencia en la que se presentó inicialmente la idea detrás de este documento, puse dos ejemplos que sirven para diferenciar la conceptualización que planteo. En el primero de ellos, mencionaba una práctica adoptada por una empresa fabricante de ropa deportiva, que en su proceso de producción utiliza un componente químico que hace que sus prendas duren un mayor tiempo, pero al mismo tiempo genera residuos tóxicos dañinos para el agua. Sin embargo, después de obtener un buen resultado de ventas, decidió contribuir con la comunidad en la que funciona, para lo cual hace una donación de una biblioteca a la escuela del municipio más cercano a su fábrica.

El segundo ejemplo mencionado hacía relación a una empresa ubicada a las afueras de la ciudad, cuyo horario laboral es de 8 de la mañana a 6 de la tarde y que con el propósito de facilitar a sus trabajadores sus desplazamientos desde y hacia el trabajo implementó un servicio de transporte que acercaba a los trabajadores a un punto central de la ciudad para evitar el tráfico en horas pico. Al hacerlo, sus trabajadores reducían los tiempos de desplazamiento desde y hacia el trabajo.

Los ejemplos resaltan que si bien la primera de las conductas es beneficiosa para la comunidad recipiente de la donación, esta no es una práctica de responsabilidad social de la empresa al no estar relacionada con el desarrollo de su objeto social tradicional.

14 En Colombia, el Pacto Global viene realizando la publicación Casos para la construcción de un mundo mejor. El compromiso empresarial para la Arquitectura Post 2015, en conjunto con la Universidad Externado de Colombia en la que se destacan casos de éxito en materia de prácticas empresariales sostenibles. La Cámara de Comercio Colombo Británica patrocina una publicación similar bajo el programa Britcham Lazos. 
da regalos a grupos de personas necesitadas. No obstante, el énfasis de lo que se debe entender por RSE debe estar en la inclusión de los efectos de la actividad de cada empresa sobre sus propios grupos de interés y en el desarrollo de su propia actividad empresarial.

De otro lado, antes de terminar esta parte en la que pretendo conceptualizar la responsabilidad social empresarial, es pertinente hacer unas consideraciones acerca de la ubicación temática de la RSE dentro de la responsabilidad como área de estudio jurídico.

Al respecto, una primera anotación debe considerar que la expresión responsabilidad social empresarial proviene de su equivalente en el mundo anglosajón (Corporate Social Responsibility), en la que el vocablo utilizado es "responsibility", en lugar del que usualmente se considera una traducción adecuada de lo que entendemos por responsabilidad: "liability". Sin embargo, también en términos generales, la definición del primero de estos dos vocablos usa como primera referencia al segundo ${ }^{15}$. Ahora bien, ante esta aparente identidad de significado, cuando se utiliza la expresión "responsibility", para saber si estamos dentro del ámbito propio del derecho hay que agregar el adjetivo "legal", de modo que sea claro que se está haciendo referencia a un deber jurídico de asumir las consecuencias de un hecho, en los términos en que así esté previsto por reglas de derecho ${ }^{16}$. Así descrita la responsabilidad, con este adjetivo, nos encontramos en el campo propio de la responsabilidad como la entendemos en el derecho europeo continental, en el que

15 Bryan A. Garner, ed., Black's Law Dictionary, 1314 (7 $7^{\mathrm{a}}$ ed., West Group, Saint Paul, Minnesota, 2003).

16 Al respecto, basta citar las referencias hechas por el profesor Hart, quien reconociendo la complejidad de la palabra responsabilidad, utiliza el adjetivo jurídico para precisar su significado: "As for the ambiguities of the word 'responsibility', ... it is, I think, still important to distinguish two of the very different things this difficult word may mean. To say that someone is legally responsible for something often means only that under legal rules he is liable to be made either to suffer or to pay compensation in certain eventualities. The expression 'he'll pay for it' covers both these things. In this primary sense of the word, though a man is normally only responsible for his own actions or the harm he has done, he may be also responsible for the actions of other persons if legal rules so provide. Indeed in this sense a baby in arms or a totally insane person might be legally responsible - again, if the rules so provide-; for the word simply means liable to be made to account or pay and we might call this sense of the word 'legal accountability' [...]”. Herbert Lionel Adolphus HART, Changing Conceptions of Responsibility, en Punishment and Responsibility: Essays in the Philosophy of Law, Chapter VIII, 186, 196-197 (Oxford University Press, Oxford, 1968), citado por Bryan A. Garner, ed., Black's Law Dictionary (7 $7^{\mathrm{a}}$ ed., West Group, Saint Paul, Minnesota, 2003). Itálicas propias. 
seguramente la expresión más acertada sería la de la responsabilidad civil ${ }^{17}$.

Por el contrario, o mejor aún, en el mismo sentido explicado anteriormente, en la medida en que a la expresión responsabilidad se le cambia el adjetivo ("legal responsibility" frente a "social responsibility"), ya no estamos propiamente ante un deber jurídico de conducta, sino ante un deber que tiene su origen principal en consideraciones sociales, según lo mencionaba en la segunda parte de este documento.

De esta forma, los elementos propios de la relación de responsabilidad, entendida en términos jurídicos, no resultan aplicables, en principio, a la referida RSE. Por supuesto, es posible que en el desarrollo de actividades propias de la RSE se presenten eventos de responsabilidad civil imputables a la empresa, lo que no significa que al hablar de la RSE estemos en un tema en el que se haya causado un daño cierto, se pueda imputar el mismo y surja el deber jurídico de repararlo. Se reitera entonces que la RSE hace más bien referencia a un deber que surge de la realidad social en la que se desarrolla la actividad de la empresa, lo que no significa que necesariamente sea un asunto absolutamente voluntario o carente de implicaciones jurídicas.

\section{DIFICULTADES JURÍdICAS DE LA RSE: LA PRIORIZACIÓN DE LOS GRUPOS DE INTERÉS Y SU CARÁCTER VOLUNTARIO}

Pongo de presente en este documento que, a pesar del auge del tema de la RSE y de ser un tema de indudable vigencia desde una

17 Pertinentes al respecto resultan las consideraciones hechas por el profesor Juan Carlos Henao en el Prefacio de su libro sobre el daño resarcible, para circunscribir la temática de su libro: "Dentro de las múltiples opciones que tienen las sociedades para hacer frente a los daños interesa en este escrito, entonces, la que se desarrolla a través del litigio de responsabilidad civil, porque centra jurídicamente el concepto. Se trata en efecto, de averiguar cuándo el daño sufrido por una persona debe ser resarcido a la culminación de un proceso judicial o preventivamente por medio de una conciliación. Las otras formas, la solidaridad social, las donaciones, los sistemas de seguridad social, etc., por ejemplo, son interesantes desde las perspectivas política, sociológica y económica, pero no tienen incidencia directa en el estudio del daño resarcible con base en la responsabilidad civil". Juan Carlos Henao, El daño. Análisis comparativo de la responsabilidad extracontractual del Estado en derecho colombiano y francés, 29 (Universidad Externado de Colombia, Bogotá, 1998). Itálicas propias. 
perspectiva de administración de empresas, algunos puntos hacen de su aplicación jurídica un reto aún no resuelto.

En primer lugar, frente al tema de la existencia de diversos grupos de interés que resultan afectados por una empresa, desde el punto de vista jurídico resulta identificable la preocupación de si existe o debería existir un grado de priorización entre múltiples grupos afectados por una misma empresa. Es decir, si una empresa afecta al medio ambiente pero así mismo afecta a la comunidad en la que funciona, ¿deberá decidir entre actuar en primera medida frente a uno u otra? Para ser más contundente, cabría la pregunta de si el medio ambiente es prioritario frente a la comunidad ${ }^{18}$.

Por supuesto, no existe una respuesta categórica en abstracto. Sin embargo, esto evidencia la imposibilidad de establecer reglas jurídicas de prioridad o importancia de los grupos de interés, lo que por supuesto hace difícil la consagración de pautas normativas o de juicios de responsabilidad.

Justamente, de forma correlativa, y en razón a que se trata de temas aún en discusión, la tendencia académica prevaleciente tiende a considerar que las normas en materia de RSE tienen un carácter voluntario. Teniendo en cuenta que su conceptualización no es pacífica, ni tampoco lo es su alcance, se ha pretendido defender la noción de la RSE como un asunto de compromisos voluntarios de las empresas. Si bien esto es cierto, no lo es menos que tal carácter voluntario no es absoluto, o que hay espacios en los que este se viene desdibujando.

Este punto, que resulta de particular interés para el análisis jurídico, se puede evidenciar en el alcance que pueden tener, frente a terceros, los compromisos o declaraciones de comportamientos socialmente responsables que hacen las empresas. Así, considero que sería perfectamente posible derivar efectos jurídicos vinculantes para las empresas de las declaraciones de adhesión a pactos o convenios en materia de RSE, si los terceros utilizan tales declaraciones como motivación para tomar ciertas decisiones contractuales como podrían ser decisiones de inversión, de consumo, operaciones de

18 Una empresa que decide hacer un cambio tecnológico mediante el cual ahorra sustancialmente en agua y energía, lo que por supuesto beneficia al medio ambiente, pero que como consecuencia de ello debe despedir a varios trabajadores que ya no son necesarios en la actividad de la empresa, ¿podría ser considerada socialmente responsable? 
financiación, o la inclusión como criterio de selección de contratistas con base en la aplicación de prácticas de RSE para mencionar algunos eventos. En estos casos, tales compromisos adquieren un carácter vinculante derivado de su aplicación en relaciones contractuales particulares.

De otro lado, en la medida en que los grupos de interés que se pueden ver afectados por el desarrollo del objeto de una empresa hacen parte de áreas que en derecho se tratan de manera diferenciada, es posible identificar cómo en algunos de estos campos (en unos más que en otros), los instrumentos normativos vinculantes son numerosos. Lo anterior se debe a que los grupos de interés organizados han logrado una presión que ha llevado a que los esfuerzos legislativos nacionales y de organismos internacionales de alguna forma vayan incorporando normas encaminadas a proteger los intereses de los grupos que defienden. Baste al efecto mencionar la existencia de normas en materia laboral, protección al consumidor, de seguridad industrial, de medio ambiente, e incrementalmente de derechos humanos, en las que ya existen normas nacionales e internacionales que son aplicables al desarrollo de las actividades empresariales $^{19}$.

Justamente, la imposibilidad de priorizar entre los diferentes grupos de interés ha hecho que el desarrollo normativo de cada uno de tales grupos se haga de forma separada, y sea la empresa la que deba someterse a un ejercicio permanente de adaptación o cumplimiento de los consensos normativos que se generan en los estados en los que funciona.

Ante esta dificultad normativa aparente para regular el tema de la RSE y el impacto de la empresa frente a sus grupos de interés como un conjunto, se ha considerado que la tendencia normativa más adecuada debe ser la de la autorregulación de las empresas. Con esta tendencia, los reportes de información en temas no financieros o de sostenibilidad y las medidas de gobierno societario son las principales herramientas que vienen adoptando las empresas para

19 No en vano las empresas abordan de forma particular los riesgos de cumplimiento de normas, a tal punto que los oficiales de cumplimiento (compliance) son cargos frecuentes en empresas, en especial si tienen un carácter multinacional. 
reflejar sus compromisos de desarrollo sostenible y tranquilizar la presión pública de exigir regulación estatal vinculante ${ }^{20}$.

Esa dificultad de priorización de los grupos de interés es justamente uno de los varios problemas que enfrenta el derecho societario para justificar o implementar la RSE como un mecanismo de gobierno societario, como examinaremos a continuación.

\section{IMPLICACIONES PARA EL DERECHO SOCIETARIO DEL DISCURSO DE LA RSE}

El asunto de la RSE (aunque haya recibido otras denominaciones) no es, en estricto sentido, nuevo para el derecho societario. En efecto, la concepción del derecho empresarial como una modalidad que abarca de forma transversal áreas como el derecho laboral, tributario y el societario propiamente dicho es común en el derecho europeo continental y, desde el punto de vista regulatorio, las tendencias que propenden a una conjugación entre el derecho económico y el derecho social son frecuentes.

No obstante otras consideraciones jurídicamente que pueden hacerse relacionadas con el tema de la RSE, en materia de derecho societario el punto en últimas se refiere a si los administradores tienen el deber de ejecutar la actividad social a favor de los mencionados grupos de interés. Al respecto, de forma particular vale la pena resaltar la tendencia identificada por los profesores estadounidenses Adolf Berle y E. Merrick Dodd, quienes sin hacer una mención expresa a lo que acá referimos como RSE, buscaron determinar cuál debía ser el rol que los administradores societarios debían desplegar con relación a los accionistas y a otros grupos directamente influenciados por la empresa. Así, mientras el primero sostuvo una visión en la misma línea de lo que hoy conocemos como el modelo de la Primacía de los accionistas al decir que las actuaciones de los administradores de una sociedad comercial debían estar guiadas por lo que resultara más beneficioso para todos sus socios; el segundo afirmaba que con el propósito de dar una mayor

20 Sobre los argumentos de la regulación o autorregulación en materia de RSE y los reportes de información no financiera, me remito a las consideraciones hechas en otro trabajo: FABIO ANDRÉs Bonilla-SANABRIA, CSR and CSR Reporting. Reporting as a Way of Creating Socially Responsible Business, 10 Revista e-Mercatoria, 22, 123-162 (2011). Disponible en: http://www.emercatoria.edu. co/PAGINAS/VOLUMEN10/PDF02/127.pdf 
flexibilidad a los administradores para actuar en consideración de los intereses de otros grupos, debía enfatizarse que la posición de los administradores no era la de mandatarios (agents) de los socios, sino la de mandatarios de la sociedad comercial como ente jurídico independiente ${ }^{21}$. Sin embargo, y en esto coincidían ambos profesores, jurídicamente no parecía haber una doctrina alternativa suficientemente clara y desarrollada que permitiera sustituir la prevalencia de los socios o accionistas dentro de la estructura de la empresa como criterio para diseñar herramientas de gobierno societario (corporate governance).

Así, el asunto de la RSE y la pregunta “ ¿a favor de quién deben administrarse las empresas?" se resuelven en términos jurídicos al responder "¿a quién deben los administradores de una sociedad comercial sus deberes como tales?". Por supuesto, cuando el asunto es planteado en estos términos, la RSE se vuelve un problema de gobierno societario ${ }^{22}$ que, a decir verdad, no se ha resuelto de forma definitiva pero se ha analizado repetidamente.

La tendencia mayoritaria desde el punto de vista del derecho societario (con principal influencia del derecho societario del common law) continúa siendo la de sostener la prevalencia del interés de los aportantes de capital como grupo que debe guiar o ser tenido en cuenta para establecer el denominado interés social de la empre$\mathrm{sa}^{23}$. Ahora bien, si se considera que en efecto hay una tendencia

21 La posición de estos profesores es explicada en estos términos por Joseph L. WeInER, The Berle-Dodd Dialogue on the Concept of the Corporation, 64 Columbia Law Review, 8, 1458-1467 (1964). Disponible en: http://basesbiblioteca.uexternado.edu.co:2088/HOL/Page?public=false \&handle=hein. journals/clr64\&collection=journals\&id=1492

22 La tendencia a hablar de gobierno corporativo - cuando la traducción apropiada tal vez sería la de gobierno societario - tiene tal impacto que para facilitar la claridad conceptual muchos autores han sucumbido y aceptado el anglicismo. En este punto, sin embargo, adopto los comentarios del profesor Francisco Reyes-Villamizar, que ha llamado la atención frente a la necesidad sobre la claridad conceptual y gramatical al utilizar expresiones anglosajonas. Al respecto, FrANCISCO Reyes-Villamizar, Derecho societario en Estados Unidos. Introducción comparada, prefacio de la tercera edición (Publicaciones Legis, Bogotá, 2006).

23 El modelo de la primacía de los accionistas recibió críticas desde el punto de vista económico con base en el planteamiento hecho por Margaret M. Blair y Lynn A. Stout, quienes consideran que el derecho societario no trata a los administradores como maximizadores del valor de las acciones, sino como intermediarios encargados de regular y favorecer los intereses de todos los que tienen una "inversión" en la compañía (incluyendo acreedores, proveedores y trabajadores). MARGARET M. Blair \& Lynn A. Stout, A Team Production Theory of Corporate Law, 85 Virginia Law Review, 2, 247-328 (1999). Disponible en: https://www.business.illinois.edu/josephm/BA549_Fall\%202016/ Session\%204/4_Blair_Stout\%20(1999).pdf. Este modelo, sin embargo, ha sido analizado detalladamente en cuanto a su alcance y descartado frente a la teoría de la primacía de los accionistas por Stephen M. Bainbridge, Director Primacy: The means and ends of Corporate Governance 
convergente del derecho societario comparado hacia este modelo ${ }^{24}$, y la profecía del fin del derecho societario se hubiera cumplido, no tendría sentido continuar la indagación acerca de la existencia de un modelo normativo que sustente la aplicación de la RSE. Sin embargo, en algunos casos concretos, la ley o los pronunciamientos judiciales (nacionales y extranjeros) han desarrollado una visión amplia del interés social, lo que permite cuestionar, aunque sea marginalmente, si el modelo de la primacía de los accionistas seguirá siendo prevaleciente.

Considero importante mencionar dos casos a este respecto. En primer lugar, la regulación que al efecto consagra el Código de Sociedades del Reino Unido, y por supuesto la existente en nuestro ordenamiento jurídico nacional ${ }^{25}$.

\section{A. El caso del Reino Unido}

En el Reino Unido, el artículo 172 del Código de Sociedades (Companies Act de 2006) ${ }^{26}$ de manera expresa responde la pregunta de a quién deben los administradores sus deberes como tal, y al hacerlo parece tomar la posición ya establecida vía jurisprudencial,

(University of California, Los Ángeles, UCLA, School of Law Research Paper, 02-06, 2002). Disponible en https://papers.ssrn.com/sol3/papers2.cfm?abstract_id=300860. Así mismo, el modelo de primacía de los accionistas ha sido recientemente replanteado o interpretado, de modo que no hay una incompatibilidad fundamental con la existencia de otros grupos de interés y su eventual defensa por parte de los administradores sociales.

24 Hago referencia al artículo de Henry Hansmann \& Reinier Kraakman, The End of History for Corporate Law (Yale Law School Working Paper 235; NYU Working Paper 013; Harvard Law School Discussion Paper 280; Yale SOM Working Paper ICF-00-09, January 2000). Disponible en: http:// ssrn.com/abstract $=204528$

25 Si bien en el Derecho de Estados Unidos no hay normas societarias como las que se pasará a revisar en el caso británico, ello no significa que no haya en ese derecho antecedentes sobre el interés social entendido de forma amplia para incluir grupos de interés diferentes al de los aportantes de capital. Así, por ejemplo, la fallida experiencia de los Constituency Codes evidencia un primer antecedente. Para un comentario sobre tales códigos: ANDREw R. KEAY, Moving Towards Stakeholderism? Constituency Statutes, Enlightened Shareholder Value and All That: Much Ado about Little? (Working Paper, 4 January 2010). Disponible en: https://papers.ssrn.com/sol3/papers2.cfm?abstract_id=1530990 y Fabio Andrés Bonilla-SAnabria, CSR and CSR Reporting. Reporting as a Way of Créating Socially Responsible Business, 10 Revista e-Mercatoria, 22, 123-162, 132 (2011).

Adicionalmente, en la legislación estatal, vale la pena mencionar la experiencia del estado de California, replicada en otros estados, cuya forma de tratar el asunto no ha sido mediante la reforma de los deberes de los administradores, sino que se ha resuelto crear tipos societarios especiales diseñados de forma expresa para permitir una administración a favor de otros stakeholders (estos tipos societarios se conocen como benefit corporations).

26 Reino Unido, Companies Act 2006, Chapter 46. Disponible en: http://www.legislation.gov.uk/ ukpga/2006/46/pdfs/ukpga_20060046_en.pdf 
conforme con la cual los administradores deben sus deberes a la sociedad que administran y no a los accionistas de la misma ${ }^{27}$. En efecto, la parte inicial del mencionado artículo señala que un administrador debe actuar en la forma en que él considere, de buena fe, que promueve el éxito de la sociedad que administra, en beneficio de sus miembros entendidos como un conjunto ("A director must act in the way he considers, in good faith, would be most likely to promote the success of the company for the Benedit of its members as a whole..."). Por lo tanto, se ha entendido que esta norma opta por entender que el interés de la sociedad comercial está mejor representado por el de sus accionistas considerados como un grupo.

Ahora bien, a pesar de la aparente claridad de la norma citada, el gobierno británico decidió aprovechar la oportunidad legislativa de la reforma de 2006 para tomar posición frente al tema de si los grupos de interés diferentes a los accionistas debían ser tenidos en cuenta por los administradores al manejar una sociedad comercial. Por lo tanto, ante esta dicotomía doctrinal entre la prevalencia de los accionistas o la de los grupos de interés, consideró oportuno incluir en la reforma una posición que buscaba indicar la inexistencia de una verdadera contradicción entre los accionistas y otros grupos al momento de administrar la sociedad ${ }^{28}$. De este modo, el inciso segundo de la norma del artículo 172 comentado incluyó un apartado conforme con el cual los administradores, al buscar el éxito de la sociedad para la cual ejercen su encargo, deberán considerar, entre otros factores, el impacto de largo plazo de sus decisiones, los intereses de trabajadores, las relaciones comerciales con clientes y proveedores, el impacto de sus actividades frente a la comunidad y el medio ambiente, y el impacto sobre su reputación ${ }^{29}$.

27 Este principio se entiende incorporado en la decisión del caso Percival vs. Wright.

28 Resulta diciente que con posterioridad a la aprobación del Código de Sociedades de 2006, el Ministerio de Estado se vio en la necesidad de clarificar el entendimiento y alcance de la norma del artículo 172, para lo cual publicó un documento en materia de los deberes de los administradores y en su introducción, la entonces ministra comentaba: "The law is now based on a new approach. Pursuing the interests of shareholders and embracing wider responsibilities are complementary purposes, not contradictory ones". FABIO AndRÉs BonILLA-SANABRIA, CSR and CSR Reporting. Reporting as a Way of Creating Socially Responsible Business, 10 Revista e-Mercatoria, 22, 123-162, 133 (2011).

29 La cita completa del artículo 172 del Código de Sociedades del Reino Unido es la siguiente: "Duty to promote the success of the company. (1) A director of a company must act in the way he considers, in good faith, would be most likely to promote the success of the company for the benefit of its members as a whole, and in doing so have regard (amongst other matters) to-

(a) the likely consequences of any decision in the long term,

(b) the interests of the company's employees, 
Ahora bien, como lo explica John Lowry ${ }^{30}$, el alcance de esta disposición debe ser tomado en su justa proporción en la medida en que en realidad no abandona la teoría de la primacía de los accionistas pues siguen siendo estos, al constituirse en asamblea, los encargados de exigir a los administradores el cumplimiento o desempeño adecuado de sus deberes. Sin embargo, tal vez en este punto está la modesta contribución de la norma, que le permite a un administrador justificar su actuación en situaciones en que los accionistas cuestionen decisiones de administración que prefieran a otros grupos de interés por encima de ellos. En ese sentido, la norma funciona como eximente de responsabilidad por un incumplimiento de los deberes de administrador, sin que por ello legitime a tales grupos para exigir un comportamiento determinado de los administradores a su favor ${ }^{31}$.

Por supuesto, al lado de esta particular solución legislativa, la jurisprudencia inglesa había producido precedentes en los que había llegado a la conclusión de que, bajo circunstancias determinadas, puede incluso surgir un deber de los administradores de actuar en consideración de otros grupos, como los trabajadores, en situaciones de adquisiciones hostiles de empresas ${ }^{32}$, o de los acreedores en

(c) the need to foster the company's business relationships with suppliers, customers and others,

(d) the impact of the company's operations on the community and the environment,

(e) the desirability of the company maintaining a reputation for high standards of business conduct, and

(f) the need to act fairly as between members of the company.

(2) Where or to the extent that the purposes of the company consist of or include purposes other than the benefit of its members, subsection (1) has effect as if the reference to promoting the success of the company for the benefit of its members were to achieving those purposes.

(3) The duty imposed by this section has effect subject to any enactment or rule of law requiring directors, in certain circumstances, to consider or act in the interests of creditors of the company". Reino Unido, Companies Act 2006, Chapter 46. Disponible en: http:/www.legislation.gov.uk/ ukpga/2006/46/pdfs/ukpga_20060046_en.pdf

30 JoHn Lowry, The Duty of Loyalty of Company Directors: Bridging the Accountability Gap through Efficient Disclosure, 63 Cambridge Law Journal, 3, 607-622 (2009). Disponible en: http://discovery. ucl.ac.uk/73103/1/download7.pdf

31 Len Sealy y Sarah Worthington se refieren al efecto de esta norma como el de un escudo que protege a los administradores y no una lanza que les permita a otros grupos de interés atacarlos. LEN SEALY \& Sarah Worthington, Sealy's Text, Cases, and Materials in Company Law, 322 ( $9^{\text {th }}$ edition, Oxford University Press, OUP, Oxford, 2010).

32 La posición del juez Thomas R. Berger en el caso Teck Corporation v. Millar es un ejemplo: "If today the directors of a company were to consider the interests of its employees no one would argue that in doing so they were not acting bona fide in the interests of the company itself. Similarly, if the directors were to consider the consequences to the community of any policy that the company intended to pursue, and were deflected in their commitment to that policy as a result, it could not be said that they had not considered bona fide the interests of the shareholders". Citado por JoHn LowRY, The Duty of Loyalty of Company Directors: Bridging the Accountability Gap through Efficient 
eventos en los cuales es inminente la declaración de insolvencia de la sociedad ${ }^{33}$. Es decir, el interés social es cambiante y deberá ser determinado en cada caso, conforme con las circunstancias de la empresa ${ }^{34}$.

\section{B. La regulación en Colombia y su interpretación constitucional}

De otro lado, en materia de derecho societario, en Colombia la Ley 222 de 1995 es la encargada de definir a favor de quién se debe administrar una sociedad comercial. A ese respecto, la norma contenida en el artículo 23 establece de forma clara que las actuaciones de los administradores deberán realizarse en interés de la sociedad para la cual ejercen su cargo, considerando el interés de sus socios ${ }^{35}$. Es decir, el interés social conforme con esta ley debe tener como principal referente el interés de los socios, planteamiento que, dicho sea de paso, resulta coherente con la legitimación que el artículo 25 de la misma ley entrega a los accionistas constituidos en asamblea, para decidir si se ejerce la acción social de responsabilidad a favor de la sociedad.

Disclosure, 63 Cambridge Law Journal, 3, 607-622, 617 (2009). Disponible en: http://iscovery. ucl.ac.uk/73103/1/download7.pdf

33 En este punto, la situación del Reino Unido es particular considerando la existencia del artículo 214 de la Ley de Insolvencia de 1986 en la cual se regula la figura del "wrongful trading", conforme con la cual se hace responsable al administrador que de forma imprudente continúe los negocios de la sociedad comercial cuando es claro que la insolvencia es inminente, poniendo por lo tanto en riesgo el interés de los acreedores en el inevitable proceso de insolvencia que se avecina. El caso de West Mercia Safetywear Ltdv. Dodd, en el que se tomó como precedente el caso Kinsela v. Russell Kinsela Pty. Ltd. Para decir que en la insolvencia el interés de los acreedores se inmiscuye, pues en últimas los bienes de la sociedad pasarán a ser, por medio del proceso de liquidación, de los acreedores y no de los accionistas. Para comentarios sobre los casos, Len Sealy \& Sarah Worthington, Sealy's Cases and Materials in Company Law, 170 ( ( $^{\text {th }}$ edition, Oxford University Press, OUP, Oxford, 2010).

34 Esta posición no es aceptada unánimemente en la doctrina comparada. Al respecto, el profesor español Juan Sánchez-Calero Guilarte, claramente sostiene que el interés social debe ser único e inmodificable. JuAn SÁnChez-CAlero Gullarte, Creación de valor, interés social y responsabilidad social corporativa, en Derecho de sociedades anónimas cotizadas: estructura de gobierno y mercados, Tomo II, 851-914 (Fernando Rodríguez-Artigas, coord., Editorial Aranzadi, Cizur Menor, Navarra, 2006). Disponible en: http://eprints.ucm.es/5600/1/Creaci\%C3\%B3n_de_valor.pdf

35 "Artículo 23. Deberes de los administradores. Los administradores deben obrar de buena fe, con lealtad y con la diligencia de un buen hombre de negocios. Sus actuaciones se cumplirán en interés de la sociedad, teniendo en cuenta los intereses de sus asociados...". Colombia, Ley 222 de 1995, por la cual se modifica el Libro II del Código de Comercio, se expide un nuevo régimen de procesos concursales y se dictan otras disposiciones, 42.156 Diario Oficial, 20 de diciembre de 1995. Disponible en: http://www.secretariasenado.gov.co/senado/basedoc/ley_0222_1995.html 
Ahora bien, en Colombia sería posible construir un argumento interpretativo diferente. En efecto, de conformidad con la cláusula constitucional que impone una función social a la empresa (artículo 333 Constitución Política ${ }^{36}$ ) sería posible en un caso concreto argumentar que un administrador estaría válidamente ejerciendo sus deberes si llegare a considerar el interés de otros grupos de interés, incluso por encima del de los aportantes de capital. En una situación similar, cabría el interrogante de si el administrador ha ejercido adecuadamente sus deberes legales como tal y beneficiarse en los términos de la norma inglesa atrás comentada. En este sentido, no sobra mencionar que la norma legal que parece adoptar el modelo de la primacía de los accionistas es posterior a la Constitución y en ese sentido, se puede entender como su desarrollo antes que como una contradicción ${ }^{37}$. Sin embargo, resulta también pertinente mencionar que, por medio de múltiples pronunciamientos tanto vía tutela como de fallos de constitucionalidad, la Corte Constitucional ha intentado dar un alcance a la cláusula de función social de la empresa, incluso si no lo ha hecho con fundamento o en relación con el alcance del artículo 23 de la Ley 222 de 1995, para considerar que tal función social tiene un carácter complementario al ánimo de lucro propio de los entes empresariales, que por supuesto beneficio a sus aportantes de capital ${ }^{38}$.

En sus pronunciamientos, en especial conforme con una línea jurisprudencial desarrollada con las ponencias del magistrado

36 Artículo 333. “[...] La empresa, como base del desarrollo, tiene una función social que implica obligaciones. El Estado fortalecerá las organizaciones solidarias y estimulará el desarrollo empresarial...”. Colombia, Constitución Política, versión corregida 116 Gaceta Constitucional, 20 de julio de 1991. Disponible en: http://www.secretariasenado.gov.co/senado/basedoc/constitucion_politica_1991. html

37 El alcance que se le debe dar a la interpretación constitucional y legal del artículo 23 de la Ley 222 de 1995 es tratado en mayor detalle en otro artículo. Al respecto ver FABIO ANDRÉs BoniLla-SANABRIA, La responsabilidad social del consumidor: el consumidor responsable y la sostenibilidad del modelo económico, en Empresa y consumidor (en prensa, Universidad Externado de Colombia, Bogotá, 2017).

38 "La responsabilidad social como principio de acción empresarial viene a complementar, y a enriquecer, el que hasta ahora había sido el núcleo teleológico de su actividad: el ánimo de lucro. La idea de que la empresa es uno de los principales actores dentro de una comunidad y de que su actividad debe ser un instrumento de mejora social, de protección al medio ambiente y de respeto de los derechos fundamentales, entre otros elementos de construcción social, ha animado la consolidación de principios que guían la construcción de parámetros de responsabilidad social para las empresas". Colombia, Corte Constitucional, Sentencia T-247-10, 15 de abril de 2010, magistrado ponente Humberto Sierra-Porto, Consideraciones y fundamentos 7. Disponible en: http://www. corteconstitucional.gov.co/relatoria/2010/t-247-10.htm 
Humberto Sierra-Porto ${ }^{39}$, la Corte Constitucional reconoció la posibilidad de que las prácticas de RSE tengan un origen en normas imperativas, y hasta consideró deseable que las mismas fueran incluidas en tratados internacionales bilaterales como el caso del Tratado de Libre Comercio con Canadá ${ }^{40}$, pues las mismas serían un desarrollo del principio constitucional de la solidaridad y le dan un contenido específico a la cláusula de la función social que tiene la empresa. De manera particular, en un pronunciamiento cuyos alcances en el derecho societario podrían ser significativos, sostuvo la Corte, en un pronunciamiento de tutela lo siguiente: “(...) la legitimidad de una decisión empresarial no puede juzgarse únicamente a través del prisma de su autonomía. A esta visión forzosamente deberá adicionarse la consideración de sus consecuencias sociales y ecológicas" $"$.

Ahora bien, con base en una interpretación como la anterior, el juez de tutela estaría en capacidad de cuestionar las decisiones de administración de una sociedad comercial, por ejemplo, cuando estas afectan a sus grupos de interés. Esto por supuesto sería a nuestro entender exagerado y se debe tomar con un alto grado de cuidado, pues implicaría una intromisión indeseada por parte de los jueces en decisiones de carácter empresarial y cuyo contenido principalmente (si bien no exclusivamente) corresponde a un ámbito de la autonomía privada, desarrollada dentro del alcance normativo de cada caso ${ }^{42}$.

39 Al respecto: Colombia, Corte Constitucional, Sentencia C-608-10, 3 de agosto de 2010, magistrado ponente Humberto Sierra-Porto. Disponible en: http://www.corteconstitucional.gov.co/ relatoria/2010/C-608-10.htm. Colombia, Corte Constitucional, Sentencia C-915-10, 16 de noviembre de 2010, magistrado ponente Humberto Sierra-Porto. Disponible en: http://www.corteconstitucional. gov.co/relatoria/2010/c-915-10.htm. Colombia, Corte Constitucional, Sentencia T-247-10, 15 de abril de 2010, magistrado ponente Humberto Sierra-Porto. Disponible en: http://www.corteconstitucional. gov.co/relatoria/2010/t-247-10.htm

40 Colombia, Corte Constitucional, Sentencia C-608-10, 3 de agosto de 2010, magistrado ponente Humberto Sierra-Porto. Disponible en: http://www.corteconstitucional.gov.co/relatoria/2010/C-608-10. htm

41 Colombia, Corte Constitucional, Sentencia T-375-97, 14 de agosto de 1997, magistrado ponente Eduardo Cifuentes-Muñoz. Disponible en: http://www.corteconstitucional.gov.co/relatoria/1997/t-375-97. htm

42 Si bien una parte de la doctrina nacional ha afirmado que la teoría de la discrecionalidad de los administradores no resulta aplicable al ordenamiento colombiano, en particular a su régimen de responsabilidad civil (Luis Fernando SABOgal, El margen discrecional de los administradores en Colombia: ¿es aplicable la "regla del buen juicio empresarial” en el ámbito de su deber de diligencia?, 11 Revista e-Mercatoria, 1, 102-163 (2012). Disponible en: http://revistas.uexternado.edu. co/index.php/emerca/article/view/3202/2848), en lo personal considero que no solo sí sería posible aplicar esta doctrina, sino que además ello sería deseable, pues no puede considerar el juez que 


\title{
V. EL ROL DE LA EMPRESA DE GRUPO FRENTE A LA RESPONSABILIDAD SOCIAL EMPRESARIAL
}

\author{
Ahora bien, consciente de que el enfoque de este documento tam- \\ bién incluye el papel o la influencia de la doctrina de la RSE en la \\ empresa de grupo, en este punto haré algunas consideraciones al \\ respecto.
}

\section{A. La RSE como parte de la unidad de propósito y dirección}

Según se explicó, en la actualidad, el diseño de las prácticas y en especial de la regulación en materia de gobierno societario está marcada prevalentemente por la idea de que los aportantes de capital, si bien no son el único grupo de interés afectado por el desarrollo de la empresa, siguen siendo el norte más claro para su control y funcionamiento $^{43}$ (admito que se trata de un debate vigente en materia

tiene una capacidad de administración mayor que la de los profesionales expresamente nombrados para tomar decisiones.

Adicionalmente, en Colombia ya hay sentencias en las que se mencionan las bases de un principio de no intervención por parte del juez en la administración de una sociedad, gracias al reciente desarrollo de la jurisprudencia societaria por parte de la Delegatura de Procedimientos Mercantiles de la Superintendencia de Sociedades (me refiero en particular al caso Pharmabroker C.I., Aldemar Tarazona y otras contra Alexander Illich León Rodríguez y al caso Loyalty Marketing Services Colombia S.A.S. contra Shirley Natalia Ávila), en la que parece empezar a sentar las bases del alcance de tal principio, de modo que salvo la existencia de situaciones de ilegalidad, al juez societario no le corresponde inmiscuirse en las decisiones de administración. Así mismo, resulta pertinente mencionar las reformas que han sido anunciadas en foros públicos por la actual administración de la Superintendencia. Al respecto, ver las conferencias publicadas por la Superintendencia de Sociedades sobre el tema Responsabilidad de los Administradores en http://livestream.com/supersociedades/ ResponsabilidaddelosAdministradores

43 En efecto, el modelo orientado hacia el accionista, prevaleciente en países anglosajones, sigue teniendo gran impacto, debido tal vez a las dificultades que presentan otros sistemas. Sin embargo, el mismo está lejos de ser un ideal absoluto, sobre todo cuando en años recientes se han evidenciado sus fallas para corregir problemas como los conflictos de interés, el insider dealing o los excesos o abusos en materia de remuneración de administradores. Al respecto, el debate ahora parece no ser tanto el de establecer qué grupo de interés debe prevalecer en una sociedad comercial, sino el de buscar formas en que la creación de valor promueve intereses de largo plazo. La discusión acerca de la promoción de políticas de administración destinadas a generar valor de largo plazo es tal vez uno de los temas actuales en materia de gobierno societario en la doctrina comparada. Lejos de existir un consenso, resulta provechoso estar al tanto de las discusiones. JANET WiLliamson, Ciaran Driver \& Peter Kenway, eds., Beyond Shareholder Value. The Reasons and Choices for Corporate Governance Reform (Trades Union Congress, TUC, New Policy Institute, NPI \& School of Oriental and African Studies, SOAS, University of London, London, 2014). Disponible en: https://www.tuc. org.uk/publications/beyond-shareholder-value-reasons-and-choices-corporate-governance-reform. Michael Porter \& Mark R. Kramer, Creating Shared Value, 89 Harvard Business Review, 1-2, 62-77 (January-February 2011). Disponible en https://hbr.org/2011/01/the-big-idea-creating-sharedvalue 
de corporate governance). Desde esta perspectiva, los avances que la regulación ha tenido con relación a comportamientos empresariales frente a cada uno de los grupos de interés, están limitados por los consensos democráticos que se alcancen en cada sociedad y que se reflejan en regulaciones específicas en materia laboral, de consumidores, ambientales y sociales.

Sin embargo, estos consensos democráticos no se han logrado y la RSE sigue siendo, en principio, de acuerdo con los comentarios hechos atrás, un tema aspiracional que depende de la voluntad de cada empresa y de los valores organizacionales que ha decidido adoptar e implementar. Es decir, la RSE sigue siendo residualmente voluntaria. Ahora bien, con esta premisa, entendiendo que la regulación no puede lograr la generalización o expansión de prácticas empresariales socialmente responsables, en todo caso la estructura de la empresa de grupo tal vez está especialmente diseñada para permitir que esas prácticas voluntarias tengan un mayor impacto. Así, y en la medida en que el funcionamiento de la empresa de grupo supone una coordinación de actividades entre las diferentes unidades económicas que pertenecen a ella, el rol que la empresa como unidad grupal quiere tener frente a sus grupos de interés puede formar parte de la llamada unidad de propósito y dirección.

No obstante, si bien es evidente el mayor impacto que tendría una política de RSE aplicada a una empresa de grupo, esta política significa un reto incluso más exigente que el que representaría su adopción para empresas no grupales. En efecto, en la medida en que la administración del grupo deberá considerar el impacto sobre los stakeholders de todas y cada una de las unidades que pertenecen al mismo grupo, hay una clara probabilidad de que se presenten situaciones de conflicto entre los grupos de interés de diferentes unidades del mismo grupo empresarial ${ }^{44}$.

Por supuesto, hay una alternativa de que la RSE no sea una política de grupo sino un comportamiento dejado a la discrecionalidad de cada una de las empresas que pertenecen al grupo o, incluso, la posibilidad de que mediante la implementación de una

44 Las dificultades en este punto resultan similares a las de la regulación de los conflictos de interés en las situaciones de grupo. Al respecto, considero de gran utilidad por su síntesis en un asunto tan complejo, el artículo del profesor KLAUS J. Hopt, Groups of Companies. A Comparative Study on the Economics, Law and Regulation of Corporate Groups (European Corporate Governance Institute, ECGI, Law Working Paper 286/2015, 2015). Disponible en: http://ssrn.com/abstract=2560935 
célula aislada dentro de ese grupo, se desarrollen actividades que corresponden a asuntos de filantropía empresarial. En este último evento, tal como lo señalo arriba al buscar una mayor claridad conceptual de la RSE, para que pueda afirmarse acertadamente la existencia de un grupo empresarial socialmente responsable, la RSE debe consistir en una verdadera política de grupo y hacer parte de la unidad de propósito y dirección que le es aplicable.

\section{B. La RSE como un deber de los administradores de la empresa de grupo}

Con relación a los deberes de los administradores de sociedades que hacen parte de una empresa de grupo, la pregunta de frente a quién deben sus deberes como tales, esto es, si a la sociedad subordinada de la que son administradores o al grupo empresarial, la respuesta usualmente ha sido que los deben a aquella. Esto significa que dentro de la estructura de los grupos de empresas, los administradores de cada una de las unidades que la conforman deben sus deberes a la persona jurídica particular frente a la cual operan como tales y no frente a la unidad económica que conforma el grupo empresarial. Esto es así en la medida en que la figura de la empresa de grupo no crea en sí misma una persona jurídica, lo que tiene consecuencias deseables en materia de estructuración financiera y mitigación del riesgo.

Sin embargo, en la práctica comercial se presenta un principio de "adaptación legal a la realidad" ${ }^{45}$ en el sentido de que, a pesar de que cada empresa miembro de un grupo es legalmente una entidad separada, no se ignora por completo la inevitable pertenencia de la sociedad a una unidad económica. Así, y en lo que a los deberes de los administradores se refiere, en la medida en que los mismos deben ser ejercidos a favor de la sociedad, según el interés de los socios (con fundamento en la prevalencia de los socios como grupo de interés), el administrador de una sociedad subsidiaria podrá

45 "Despite the fact that, as these examples illustrate, company law does not completely ignore intra-group relationships between companies and there is some 'legal adaptation to reality', the overriding general legal principie that all companies are separate and distinct entibies and are not, in law, a single enterprise even where they are part of a Group, continues to exert a powerful force". Eilís Ferran, Principles of Corporate Finance Law, 32 ( $1^{\text {st }}$ edition, Oxford University Press, OUP, London, 2008). 
ejercer sus deberes en beneficio del grupo y no exclusivamente de la sociedad que lo designó como administrador. Por supuesto, en estos eventos, la actuación de un administrador de una sociedad subordinada deberá expresamente estar motivada por la persecución del interés de grupo, de modo pues que un eventual juicio de responsabilidad por incumplimiento de los deberes como administrador sea defensable ${ }^{46}$.

Esto significa que, partiendo de la base de que la empresa de grupo adopte una política de RSE como parte de su unidad de propósito y dirección, los administradores de sociedades subordinadas están protegidos frente a reclamaciones de negligencia en el ejercicio de sus deberes, si deciden realizar actos que pueden ser contrarios a la sociedad subordinada o contrarios a los intereses particulares de los accionistas minoritarios de la misma, esto siempre y cuando su actuación busque de forma clara y expresa la aplicación de la política de RSE adoptada por el grupo del que forma parte. En sentido contrario, la ausencia de una política grupal en materia de RSE haría más difícil justificar la actuación de los administradores de sociedades subordinadas de alejarse del interés de sus accionistas excusándose en políticas de sostenibilidad grupales.

\section{La homogeneización de prácticas empresariales en los grupos multinacionales y el efecto transnacional de la regulación que les es aplicable}

En tercer lugar, considerando que la práctica comercial de la empresa de grupo tiene una tendencia a expandir su campo de acción más allá de las fronteras de un país en particular, las empresas de grupo tienden a ser multinacionales y con ello enfrentan la existencia de culturas de negocios, estándares empresariales y en general prácticas que difieren sustancialmente de aquellas aplicables en el país de su sede principal. Para adaptarse a estas circunstancias,

46 Al comentar la situación particular del derecho alemán, el profesor Hopt menciona el deber de compensación que surge para la sociedad matriz cuando las decisiones de grupo afectan a alguna de las subsidiarias. Al respecto, el particular informe de grupo que si bien debe existir, no es de conocimiento de las subsidiarias o de las accionistas; esta es otra de las formas regulatorias en las que el derecho alemán ha buscado regular los conflictos de interés en materia de grupos empresariales. Klaus J. Hopt, Groups of Companies. A Comparative Study on the Economics, Law and Regulation of Corporate Groups, 18 y ss. (European Corporate Governance Institute, ECGI, Law Working Paper 286/2015, 2015). 
los grupos empresariales suelen desarrollar valores o prácticas homogéneas al grupo sin importar el lugar en donde funcione ${ }^{47}$. Esta práctica significa entonces en alguna medida una exportación de prácticas empresariales aplicables a países en donde empieza a tener funcionamiento el grupo y que, en el mejor de los casos, puede ocasionar la mejora de las prácticas empresariales en otros países (una carrera a la cima de prácticas empresariales ${ }^{48}$ ).

Esta tendencia relacionada con la RSE significa que si en la sede principal del grupo hay prácticas voluntarias ya desarrolladas en las que los grupos de interés de la empresa son tenidos en cuenta de forma activa, esas prácticas serían trasplantables a los demás países en donde funciona el grupo empresarial.

Adicionalmente, el trasplante de prácticas socialmente responsables se puede deber a los efectos regulatorios transnacionales de normas provenientes de otros países o de organizaciones internacionales. A título de ejemplo, la ley estadounidense en materia de prácticas de corrupción en el extranjero (Foreign Corrupt Practices $A c t)^{49}$, que tiene un equivalente británico, y conforme con las cuales las empresas multinacionales que tengan sede en Estados Unidos o en el Reino Unido, deben dar plena aplicación a las disposiciones de esas leyes, incluso si se trata de actuaciones que ocurren en otro país. Igualmente, de forma también cercana a la práctica empresarial colombiana (debido al interés del gobierno nacional de entrar a esa organización), la guía de la OCDE para empresas multinacionales impone un deber a empresas que funcionen en cualquiera de los países miembros de esta organización internacional, que consiste en realizar un estudio de debida diligencia en materia de cumplimiento

47 Considero pertinente la mención a la práctica que algunos grupos internacionales como General Electric o Unilever vienen desarrollando al implementar "universidades empresariales", en el sentido de crear programas de capacitación para sus trabajadores diseñados para resolver los retos particulares de su organización. Para un comentario reciente sobre el tema: Keeping it on the company campus, The Economist, May 16, 2015. Disponible en: http://www.economist.com/news/business/21651217more-firms-have-set-up-their-own-corporate-universities-they-have-become-less-willing-pay

48 Roberta Romano, The Genius of American Corporate Law (American Enterprise Institute, AEI Studies in Regulation and Federalism, series editors, Washington, 1993). Disponible en: https:// www.aei.org/wp-content/uploads/2014/07/-the-genius-of-american-corporate-law_162946985222. pdf

49 Estados Unidos, Foreign Corrupt Practices Act, 1977, as amended, 15 U.S.C. $\S \S 78 d d-1$, et seq. Disponible en: https://www.justice.gov/sites/default/files/criminal-fraud/legacy/2012/11/14/fcpa-english. pdf 
de estándares de derechos humanos en las cadenas de suministro o abastecimiento que tengan en el mercado mundial ${ }^{50}$.

En estos eventos, a pesar de que se trata de regulación no directamente aplicable en terceros países, dado el alcance transnacional de este tipo de normas, se identifica la existencia de ejemplos regulatorios que imponen deberes de conducta a las empresas con relación a asuntos de transparencia y derechos humanos, temas tradicionalmente vistos como pertenecientes a la RSE.

\section{El acceso a fuentes de financiación socialmente responsables}

En mi opinión, hay otra razón por la cual es posible augurar una expansión de la aplicación de prácticas empresariales socialmente responsables, aunque en realidad no sea un asunto que compete de forma exclusiva a las empresas de grupo.

La RSE es un asunto que, según lo mencionado acá, busca de la empresa propender al logro de un desarrollo sostenible en su actividad económica. Sin embargo, la sostenibilidad como valor final no es un asunto que concierne exclusivamente a la empresa o en el que esta sea el único actor que pueda desempeñar algún papel. Los consumidores, por ejemplo, tienen también una posibilidad de impacto en temas de sostenibilidad y de RSE en la medida en

50 Principio IV. Derechos Humanos, párrafo 5 de la guía para empresas multinacionales de la OCDE. En particular, el comentario 45 señala lo siguiente: "El párrafo 5 recomienda a las empresas ejercer la debida diligencia en materia de derechos humanos. Este proceso implica evaluar los impactos reales o potenciales sobre los derechos humanos, integrar los resultados de dicha evaluación y poner en práctica las acciones correspondientes, hacer un seguimiento de las respuestas y comunicar las medidas tomadas para hacer frente a los impactos. La debida diligencia en materia de derechos humanos puede integrarse en los sistemas generales de gestión de riesgos de la empresa siempre que no se limiten meramente a identificar y gestionar los riesgos significativos para la propia empresa sino que incluyan también los riesgos para los titulares de estos derechos. Se trata de un ejercicio continuo ya que los riesgos relativos a los derechos humanos pueden variar con el transcurso del tiempo a medida que evolucionan las actividades de la empresa y su contexto. Los párrafos 10, 11 y 12 del capítulo titulado "Principios generales" y sus comentarios proporcionan indicaciones complementarias sobre la debida diligencia, incluso en relación con las cadenas de suministro, así como respuestas adecuadas a los riesgos que surgen en dichas cadenas de suministro". Organización para la Cooperación y el Desarrollo Económicos, OCDE, Líneas Directrices de la OCDE para Empresas Multinacionales, Revisión 2011, 38 (París, OCDE, 2013). Disponible en http://www.oecd.org/daf/ inv/mne/MNEguidelinesESPANOL.pdf. Para un comentario académico sobre el alcance de este deber de diligencia: PETER MuChlinski, The 2011 Revision of the OECD Guidelines for Multinational Enterprises: Human Rights, Supply Chains and the 'Due Diligence' Standard for Responsible Business (A4ID Series on Responsible Business, 15 November 2011). Disponible en: http://www. a4id.org/wp-content/uploads/2016/03/A4ID_NL_JUNE_2012_Final_Web.pdf 
que vienen desarrollando tendencias de un consumo responsable de productos y servicios. En el mismo sentido, es posible identificar un rol que pueden desempeñar los inversionistas en materia de sostenibilidad. Quiero detenerme brevemente en este punto para mencionar la existencia de lo que se conoce como la inversión socialmente responsable ${ }^{51}$.

Consciente de que el mercado es un gran impulsor de comportamientos, en 2005 la ONU decidió promover la adopción de los Principios de Inversión Socialmente Responsable ${ }^{52}$. La idea del documento era la de que - en el proceso de toma de decisiones de inversión - se tuvieran en cuenta estos principios como criterios socialmente responsables. Con un lenguaje aspiracional y de naturaleza voluntaria, los seis principios buscan que las empresas destinatarias de inversiones tengan en cuenta, entre otras cosas, asuntos como la publicación de información en temas ambientales, sociales y de gobierno societario; correlativamente, su adopción por inversores o fondos de inversión pone en evidencia el compromiso con la meta de sostenibilidad en el sector financiero.

A la par de los esfuerzos de la comunidad internacional, el mercado ha visto la existencia de una necesidad de promover la sostenibilidad como un valor del mercado financiero. Las bolsas de valores han creado índices para incluir empresas que tienen temas de RSE en su gobierno societario ${ }^{53}$.

En términos generales, conforme con los principios de la ONU, es evidente que el movimiento de la inversión socialmente responsable ha tenido un éxito nada despreciable, en especial si se considera que hay alrededor de 34 trillones de dólares depositados en fondos de inversiones que utilizan entre sus criterios de escogencia de inversiones factores de sostenibilidad en línea con los Principios de las Naciones Unidas ${ }^{54}$.

51 "Sustainable, responsible and impact investing (SRI) is an investment discipline that considers environmental, social and corporate governance (ESG) criteria to generate long-term competitive financial returns and positive societal impact". Tomado de la página web del Foro para la Inversión Sostenible y Responsable de Estados Unidos, http://www.ussif.org/sribasics

52 Organización de Naciones Unidas, ONU, Principios de Inversión Socialmente Responsable. Disponible en: https://www.unpri.org/, https://www.unpri.org/about/the-six-principles

53 Ejemplos de estos índices son el Nasdaq Sustainability Index, http://business.nasdaq.com/discover/ corporate-responsibility-and-sustainability o el FTSE4GOOD, http://www.ftse.com/products/ indices/ftse4good

54 http://www.ft.com/intl/cms/s/0/6fbc344e-2d17-11e3-8281-00144feab7de.html\#axzz3aDvsaxKQ 
Conforme con lo anterior, y en un mundo cuyas estructuras de mercados globales se van a integrar cada vez más, las empresas que estén interesadas en buscar alternativas de financiación o estén en búsqueda de capital, no van a ignorar la existencia de este tipo particular de fondos de inversión. Adicionalmente, estos inversionistas, que en gobierno societario se denominan institucionales, no solo exigen la existencia de principios en materia de RSE, sino que, en su posición de inversionistas institucionales, tendrían un incentivo más claro para asegurar el efectivo cumplimiento de los criterios ambientales, sociales y de gobierno que fueron determinantes para la toma de la decisión de invertir.

\section{E. E1 efecto multiplicador}

Por último, la aplicación de prácticas de RSE en el contexto de la empresa de grupo es un escenario favorable para su desarrollo, en la medida en que una de las razones del auge del tema de la RSE es la presión social que enfrentan las empresas en un mercado de capitales globalizado. Por lo tanto, en la medida en que la empresa de grupo afronta este riesgo, en especial si es un grupo transnacional, la adopción de este tipo de prácticas puede generar un efecto multiplicador o de tendencia en el mercado.

La premisa es la siguiente: las empresas de grupo adoptan prácticas socialmente responsables, debido a una mezcla entre la existencia de una verdadera cultura de sostenibilidad en el ejercicio de su actividad, y para controlar los eventos de riesgo reputacional frente a consumidores, inversionistas o el mercado en general. Adicionalmente, hay un factor de contagio de prácticas socialmente responsables que se pueden trasladar a otras empresas, estas ya no grupales. Lo que termina ocurriendo es que las empresas de grupo o las empresas influyentes de un mercado crean una tendencia que otras empresas de menores dimensiones imitan y las adoptan para estar en la misma página de lo que perciben como necesario en el mercado ${ }^{55}$.

55 "Institutional theory holds that organizacional fields tend to become isomorphic over time as a result of three kinds of pressures: mimetic, normative, and coercive. An examination of research on convergente reveals that each of these three types of pressures is at play in the case of governance convergence". Abdul Rasheed \& Toru Yoshikawa, The Convergence of Corporate Governance. Promises and Prospects, 6 (Palgrave Macmillan, London, 2012). 
Un ejemplo de la práctica nacional corresponde a la publicación de reportes de información no financiera o de sostenibilidad. Conforme con un estudio internacional reciente publicado por $\mathrm{KPMG}^{56}$, que por primera vez incluyó a Colombia, el número de empresas que ahora publica informes en materia de sostenibilidad se ha incrementado sustancialmente. Este ejemplo, más allá de cuestiones de fondo acerca de los temas reportados, evidencia la existencia de un comportamiento de mercado consistente en preparar y publicar este tipo de reportes.

De otro lado, el posible efecto multiplicador de la RSE causado por la empresa de grupo, y en general por empresas de grandes dimensiones en un mercado nacional, se puede presentar debido al interés de otras empresas más pequeñas por contratar o proveer servicios a aquellas. Esto es así, porque para poder formar parte de las cadenas de suministro y bases de datos de proveedores, las empresas se ven en la necesidad de someterse a auditorías más o menos exigentes, que incluyen expresamente entre sus criterios de evaluación, asuntos de $\mathrm{RSE}^{57}$. De esta forma, la necesidad de contratación con empresas como el Grupo Argos o Bavaria obligaría a otras empresas que en principio no están interesadas —o no las tienen entre sus prioridades - a adoptar prácticas de RSE.

56 Además de este estudio, resulta relevante la presencia en Colombia de Global Reporting Initiative, GRI, que como empresa se dedica a ofrecer asesoría en la preparación y presentación de informes que incluyan aspectos no financieros, de modo que la información así estandarizada sea mucho más útil para el mercado. Desde una aproximación académica, IrIS H.-Y. CHIU, Standardization in Corporate Social Responsibility Reporting and a Universalist Concept of CSR? - A Path Paved with Good Intentions, 22 Florida Journal of International Law, 3, 361-400 (2010). FABIo ANDRÉs Bonilla-SANABRIA, CSR and CSR Reporting. Reporting as a Way of Creating Socially Responsible Business, 10 Revista e-Mercatoria, 22, 123-162 (2011).

57 En Colombia, entidades de certificación como la Compagnie Française d'Assurance pour le Commerce Extérieur, COFACE; el Consejo Colombiano de Seguridad, códigos especiales como el de Ecopetrol, o normas de certificación como ICONTEC, exigen la adopción de comportamientos en materia de RSE. 


\section{CONCLUSIONES}

De forma muy breve, y antes que presentar conclusiones, quisiera terminar estas líneas haciendo énfasis en los siguientes puntos:

- El tema de la RSE debe su auge actual a la interacción de factores como la globalización económica y la permeabilidad del discurso de los derechos humanos en materia empresarial.

- Una conceptualización de la RSE que desarrolle las pretensiones de sostenibilidad debe estar enfocada a que las consideraciones de los grupos de interés de cada empresa se reflejen de forma particular en el desarrollo de su objeto social.

- A pesar de que los modelos de gobierno societario que parecen prevalecer siguen marcados por la primacía de los socios como principal grupo de interés de la empresa, la RSE ha servido para criticar esta tendencia (las críticas por supuesto no se limitan a esto). La definición del interés social y de la respuesta a la pregunta para quién se debe administrar una empresa no son asuntos que tengan una única respuesta o cuyo debate haya sido superado.

- En mi opinión, la empresa de grupo está particularmente diseñada para permitir un mayor impacto a la RSE entre otras razones por su tendencia a la transnacionalidad, el incremento del riesgo reputacional causado por las tecnologías de la información, sus relaciones con proveedores y contratistas y la necesidad de considerar fuentes de financiación socialmente responsables.

La sostenibilidad de las prácticas empresariales nos lleva a considerar la afirmación del profesor Ramon Mullerat al decir que el siglo XXI será tan malo, o bueno, según como la comunidad empresarial decida hacerlo ${ }^{58}$.

58 "It is not a heresy to affirm that this $21^{\text {st }}$ century world will be as bad or as good as the business community - the boards, the stockholders and the stakeholders — will decide to make it". RAMON Mullerat, A Few Concluding Remarks, en Corporate Social Responsibility: The Corporate Governance of the $21^{\text {st }}$ Century, Chapter 32, 485-486, 485 (RAmOn Mullerat, ed., Kluwer Law International $\&$ International Bar Association, London, 2005). 


\section{BIBLIOGRAFÍA}

\section{Libros}

Ferran, Eilís, Principles of Corporate Finance Law (1st edition, Oxford University Press, OUP, London, 2008).

Garner, Bryan A., ed., Black's Law Dictionary ( $7^{\text {a }}$ ed., West Group, Saint Paul, Minnesota, 2003).

Henao, Juan Carlos, El daño. Análisis comparativo de la responsabilidad extracontractual del Estado en derecho colombiano y francés (Universidad Externado de Colombia, Bogotá, 1998).

Kerr, Michael; Janda, Richard \& Pitts, Chip, Corporate Social Responsibility. A Legal Analysis (Ontario, LexisNexis, 2009).

Mullerat, Ramon, ed., Corporate Social Responsibility: The Corporate Governance of the $21^{s t}$ Century (Kluwer Law International \& International Bar Association, London, 2005).

Rasheed, Abdul \& Yoshikawa, Toru, The Convergence of Corporate Governance. Promises and Prospects (Palgrave Macmillan, London, 2012).

Reyes-Villamizar, Francisco, Derecho societario en Estados Unidos. Introducción comparada (Publicaciones Legis, Bogotá, 2006).

Rodríguez-Artigas, Fernando, coord., Derecho de sociedades anónimas cotizadas: estructura de gobierno y mercados, Tomo II (Editorial Aranzadi, Cizur Menor, Navarra, 2006). Disponible en: http://eprints.ucm.es/5600/1/Creaci\%C3\%B3n_ de_valor.pdf

Romano, Roberta, The Genius of American Corporate Law (American Enterprise Institute, AEI Studies in Regulation and Federalism, series editors, Washington, 1993). Disponible en: https://www.aei.org/wp-content/uploads/2014/07/-thegenius-of-american-corporate-law_162946985222.pdf

Sealy, Len \& Worthington, Sarah, Sealy's Cases and Materials in Company Law $\left(^{\text {th }}\right.$ edition, Oxford University Press, OUP, Oxford, 2010).

Wilburn, Kathleen \& Wilburn, Ralph, Achieving Social License to Operate Using Stakeholder Theory, 4 Journal of International Business Ethics, 2, 3-16 (2011). Disponible en: http://www.scholarspress.us/journals/JIBE/pdf/JIBE-2-2011/ v4n211-art1.pdf

Williamson, Janet; Driver, Ciaran \& Kenway, Peter, eds., Beyond Shareholder Value. The Reasons and Choices for Corporate Governance Reform (Trades Union Congress, TUC, New Policy Institute, NPI \& School of Oriental and African Studies, SOAS, University of London, London, 2014). Disponible en: https:// www.tuc.org.uk/publications/beyond-shareholder-value-reasons-and-choicescorporate-governance-reform 


\section{Contribución en obras colectivas}

Bonilla-SANABRIA, FABIo ANDRÉs, La responsabilidad social del consumidor: el consumidor responsable y la sostenibilidad del modelo económico, en Empresa y consumidor (en prensa, Universidad Externado de Colombia, Bogotá, 2017

Mullerat, Ramon, A Few Concluding Remarks, en Corporate Social Responsibility: The Corporate Governance of the $21^{\text {st }}$ Century, Chapter 32, 485-486 (Ramon Mullerat, ed., Kluwer Law International \& International Bar Association, London, 2005).

Sánchez-Calero Guilarte, Juan, Creación de valor, interés social y responsabilidad social corporativa, en Derecho de sociedades anónimas cotizadas: estructura de gobierno y mercados, Tomo II, 851-914 (Fernando Rodríguez-Artigas, coord., Editorial Aranzadi, Cizur Menor, Navarra, 2006). Disponible en: http://eprints. ucm.es $/ 5600 / 1 /$ Creaci $\%$ C3\%B3n_de_valor.pdf

Shestack, Jerome J., Corporate Social Responsibility in a Changing Corporate World, en Corporate Social Responsibility: The Corporate Governance of the $21^{\text {st }}$ Century, Chapter 6, 97-109 (Ramon Mullerat, ed., Kluwer Law International \& International Bar Association, London, 2005).

\section{Revistas}

Blair, Margaret M. \& Stout, Lynn A., A Team Production Theory of Corporate Law, 85 Virginia Law Review, 2, 247-328 (1999). Disponible en: https://www.business. illinois.edu/josephm/BA549_Fal1\%202016/Session\%204/4_Blair_Stout\%20 (1999).pdf

Bonilla-Sanabria, Fabio Andrés, CSR and CSR Reporting. Reporting as a Way of Creating Socially Responsible Business, 10 Revista e-Mercatoria, 22, 123-162 (2011). Disponible en: http://www.emercatoria.edu.co/PAGINAS/VOLUMEN10/ PDF02/127.pdf

Chiu, Iris H.-Y., Standardization in Corporate Social Responsibility Reporting and a Universalist Concept of CSR? - A Path Paved with Good Intentions, 22 Florida Journal of International Law, 3, 361-400 (2010).

Lowry, John, The Duty of Loyalty of Company Directors: Bridging the Accountability Gap through Efficient Disclosure, 63 Cambridge Law Journal, 3, 607-622 (2009). Disponible en: http://discovery.ucl.ac.uk/73103/1/download7.pdf

Muchlinski, Peter, Human Rights and Multinationals: Is there a Problem?, 77 International Affairs, 1, 31-48 (2001).

Porter, Michael \& Kramer, Mark R., Creating Shared Value, 89 Harvard Business Review, 1-2, $62-77$ (January-February 2011). Disponible en: https://hbr. org/2011/01/the-big-idea-creating-shared-value

Sabogal, Luis Fernando, El margen discrecional de los administradores en Colombia: ¿es aplicable la "regla del buen juicio empresarial" en el ámbito de su deber de diligencia?, 11 Revista e-Mercatoria, 1, 102-163 (2012). Disponible en: http:// revistas.uexternado.edu.co/index.php/emerca/article/view/3202/2848

Weiner, Joseph L., The Berle-Dodd Dialogue on the Concept of the Corporation, 64 
Columbia Law Review, 8, 1458-1467 (1964). Disponible en: http://basesbiblioteca. uexternado.edu.co:2088/HOL/Page?public=false \&handle=hein.journals/clr64\& collection=journals\&id $=1492$

\section{Working paper}

Bainbridge, Stephen M., Director Primacy: The means and ends of Corporate Governance (University of California, Los Ángeles, UCLA, School of Law Research Paper, 02-06, 2002). Disponible en https://papers.ssrn.com/sol3/papers2.cfm?abstract_ $\mathrm{id}=300860$

Hansmann, Henry \& Kraakman, Reinier, The End of History for Corporate Law (Yale Law School Working Paper 235; NYU Working Paper 013; Harvard Law School Discussion Paper 280; Yale SOM Working Paper ICF-00-09, January 2000). Disponible en: http://ssrn.com/abstract $=204528$

Hopt, Klaus J., Groups of Companies. A Comparative Study on the Economics, Law and Regulation of Corporate Groups (European Corporate Governance Institute, ECGI, Law Working Paper 286/2015, 2015). Disponible en: http://ssrn.com/ abstract $=2560935$

Keay, Andrew R., Moving Towards Stakeholderism? Constituency Statutes, Enlightened Shareholder Value and all that: much Ado about Little? (Working Paper, 4 January 2010). Disponible en: https://papers.ssrn.com/sol3/papers2.cfm?abstract_ id $=1530990$

Muchlinski, Peter, The 2011 Revision of the OECD Guidelines for Multinational Enterprises: Human Rights, Supply Chains and the $\bigotimes D$ ue Diligence $\bigotimes$ Standard for Responsible Business (A4ID Series on Responsible Business, 15 November 2011). Disponible en: http://www.a4id.org/wp-content/uploads/2016/03/A4ID_ NL_JUNE_2012_Final_Web.pdf

\section{Documentos}

Anderson, Sarah \& Cavanagh, John, The Top 200: The Rise of Corporate Power (Global Public Forum, 2000). Disponible en: https://www.globalpolicy.org/component/ content/article/221/47211.html

Organización de Naciones Unidas, ONU, Los 10 Principios del Pacto Mundial. Disponible en: http://www.pactoglobal-colombia.org/index.php/sobre-pactoglobal/los-diez-principios

Organización de Naciones Unidas, ONU, Principios de Inversión Socialmente Responsable. Disponible en: https://www.unpri.org/, https://www.unpri.org/ about/the-six-principles

Organización para la Cooperación y el Desarrollo Económicos, OCDE, Líneas Directrices de la OCDE para Empresas Multinacionales, Revisión 2011 (París, OCDE, 2013). Disponible en http://www.oecd.org/daf/inv/mne/MNEguidelinesESPANOL.pdf

Shestack, Jerome J., Glasnost and Human Rights (Annual Lecture, Rothschild Foster Human Rights Trust, 1989). Disponible en: http://www.rothschildfostertrust. 
com/materials/lecture_shestack.pdf

\section{Normatividad internacional}

Estados Unidos, Foreign Corrupt Practices Act, 1977, as amended, 15 U.S.C. §§ 78dd-1, et seq. Disponible en: https://www.justice.gov/sites/default/files/criminal-fraud/ legacy/2012/11/14/fcpa-english.pdf

Reino Unido, Companies Act 2006, Chapter 46. Disponible en: http://www.legislation. gov.uk/ukpga/2006/46/pdfs/ukpga_20060046_en.pdf

\section{Normatividad colombiana}

Colombia, Constitución Política, versión corregida 116 Gaceta Constitucional, 20 de julio de 1991. Disponible en: http://www.secretariasenado.gov.co/senado/basedoc/ constitucion_politica_1991.html

Colombia, Ley 222 de 1995, por la cual se modifica el Libro II del Código de Comercio, se expide un nuevo régimen de procesos concursales y se dictan otras disposiciones, 42.156 Diario Oficial, 20 de diciembre de 1995. Disponible en: http://www. secretariasenado.gov.co/senado/basedoc/ley_0222_1995.html

\section{Jurisprudencia internacional}

Canadá, Corte Suprema de Justicia de British Columbia, Teck Corporation v. Millar (1972) 33 D.L.R. (3d). 288.

Reino Unido, Corte Suprema de Justicia, Percival v. Wright [1902] 2 Ch 401.

Reino Unido, Corte de Apelaciones, West Mercia Safetywear Ltd v. Dodd [1988] BCLC 250 .

\section{Jurisprudencia colombiana}

Colombia, Corte Constitucional, Sentencia C-608-10, 3 de agosto de 2010, magistrado ponente Humberto Sierra-Porto. Disponible en: http://www.corteconstitucional. gov.co/relatoria/2010/C-608-10.htm

Colombia, Corte Constitucional, Sentencia C-915-10, 16 de noviembre de 2010, magistrado ponente Humberto Sierra-Porto. Disponible en: http://www. corteconstitucional.gov.co/relatoria/2010/c-915-10.htm

Colombia, Corte Constitucional, Sentencia T-375-97, 14 de agosto de 1997, magistrado ponente Eduardo Cifuentes-Muñoz. Disponible en: http://www. corteconstitucional.gov.co/relatoria/1997/t-375-97.htm

Colombia, Corte Constitucional, Sentencia T-247-10, 15 de abril de 2010, magistrado ponente Humberto Sierra-Porto. Disponible en: http://www.corteconstitucional. gov.co/relatoria/2010/t-247-10.htm 


\section{Sentencias y conceptos de la Superintendencia de Sociedades}

Superintendencia de Sociedades, Oficio 220-014835, 8 de febrero de 2013. Disponible en: http://www.supersociedades.gov.co/superintendencia/normatividad/conceptos/ conceptos-juridicos/Normatividad\%20Conceptos\%20Juridicos/32966.pdf.

Superintendencia de Sociedades, Delegatura para Procedimientos Mercantiles, Aldemar Tarazona y otras contra Alexander Illich León Rodríguez (caso Pharmabroker C.I.), Sentencia 2013-801-82, 11 de diciembre de 2013, superintendente delegado para procedimientos mercantiles José Miguel Mendoza. Disponible en: http:// www.supersociedades.gov.co/procedimientos-mercantiles/la-delegatura/ jurisdiccion-societaria/jurisprudencia/Documents/Ultimas $\% 20$ sentencias/

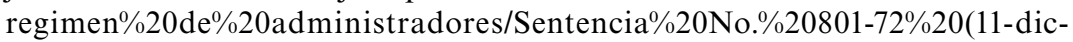
2013).pdf

Superintendencia de Sociedades, Delegatura para Procedimientos Mercantiles, Loyalty Marketing Services Colombia S.A.S. contra Shirley Natalia Ávila, Sentencia 2013-801-76, 14 de mayo de 2014, superintendente delegado para procedimientos mercantiles José Miguel Mendoza. Disponible en: http://www.supersociedades. gov.co/procedimientos-mercantiles/la-delegatura/jurisdiccion-societaria/ jurisprudencia/Documents/Sentencia $\% 20$ Loyalty $\% 20$ Marketing $\% 20$ Services. pdf

\section{Medios de comunicación}

An Interview with the President. Barack Obama Talks to the Economist, The Economist, August 2, 2014. Disponible en: http://www.economist.com/blogs/ democracyinamerica/2014/08/barack-obama-talks-economist

Keeping it on the company campus, The Economist, May 16, 2015. Disponible en: http:// www.economist.com/news/business/21651217-more-firms-have-set-up-their-owncorporate-universities-they-have-become-less-willing-pay

Financial Times, http://www.ft.com/intl/cms/s/0/6fbc344e-2d17-11e3-8281-00144feab7de. html\#axzz3aDvsaxKQ

\section{Sitios web}

Corporate Social Responsibility, http://www.csr.gov.uk

FTSE4GOOD, http://www.ftse.com/products/indices/ftse4good

Nasdaq Sustainability Index, http://business.nasdaq.com/discover/corporateresponsibility-and-sustainability

Superintendencia de Sociedades, Responsabilidad de los Administradores, http:// livestream.com/supersociedades/ResponsabilidaddelosAdministradores

The Forum for Sustainable and Responsible Investment, http://www.ussif.org/sribasics 